\title{
Cooperative $\mathrm{C}-\mathrm{H}$ Bond Activation by a Low-Spin $d^{6}$ Iron-Aluminium Complex
}

\author{
Nikolaus Gorgas, Andrew J. P. White, and Mark R. Crimmin* \\ Department of Chemistry, Imperial College London, White City, London, W12 OBZ \\ corresponding author: m.crimmin@imperial.ac.uk
}

\begin{abstract}
The reactions of transition metal complexes underpin numerous synthetic processes and catalytic transformations. Typically, this reactivity involves the participation of empty and filled molecular orbitals centred on the transition metal. Kinetically stabilised species, such as octahedral low-spin $d^{6}$ transition metal complexes, are not expected to participate directly in these reactions. However, novel approaches that exploit metal ligand-cooperativity offer an opportunity to challenge these preconceptions. Here we show that inclusion of an aluminium-based ligand into the coordination sphere of neutral low-spin $d^{6}$ iron complex leads to unexpected reactivity. Complexes featuring an unsupported $\mathrm{Fe}-\mathrm{Al}$ bond are capable of the intermolecular $\mathrm{C}-\mathrm{H}$ bond activation of pyridines. Mechanistic analysis suggests that $\mathrm{C}-\mathrm{H}$ activation proceeds through a reductive deprotonation in which the two metal centres (Fe and Al) act like a frustrated Lewis-pair. Key to this behaviour is a ground state destabilisation of the $d^{6}$ iron complex, brought about by the inclusion of the electropositive aluminium-based ligand. These findings have immediate implications for the design of reagents and catalysts based on $1^{\text {st }}$ row transition metals.
\end{abstract}

\section{Introduction.}

The concept of metal-ligand cooperativity has greatly enriched the chemistry and catalytic applications of transition metal complexes. ${ }^{1,2}$ Cooperative strategies that take advantage of the Lewis-acidic nature of a transition metal centre in combination with a Lewis basic ligand have become established features, frequently employed in the design of novel catalytic systems. Equally attractive but less common are transition metal complexes that bear a Lewis acidic functionality in the ligand. ${ }^{3-5}$ These new design principles offer an opportunity to overturn existing paradigms in transition metal chemistry. This is particularly important for applications of inexpensive and sustainable $1^{\text {st }}$ row transition metals (e.g. Fe). ${ }^{6-9}$ Despite the exciting opportunities in this field, many of the emerging reactions that involve metal-ligand cooperativity still proceed through established mechanisms, such as oxidative addition. For example, transition metal complexes bearing Lewis-acidic ligands (based on $\mathrm{B}$ or $\mathrm{Al}$ ) can activate the ortho $\mathrm{C}-\mathrm{H}$ bond of pyridine substrates (Figure 1 ). ${ }^{10-13} \mathrm{C}-$ $\mathrm{H}$ activation is believed to take place by an oxidative addition mechanism at the transition metal centre, leading to products in which the pyridyl group is directly bonded to this metal. ${ }^{13-15}$ The main group ligand plays 
a role in substrate coordination and determining the ortho selectivity, but itself does not lead to new types of reactivity.

In this paper, we report the synthesis and characterisation of bimetallic complexes in which an unsupported ${ }^{16}$ aluminium-based ligand is bound to an iron(II) dihydride fragment. These complexes are neutral low spin $\mathrm{d}^{6}$ species based on an octahedral parent geometry and as such are expected to be chemically inert. ${ }^{17}$ Textbook examples of such compounds with more classical ligand systems possess a stable 18-electron configuration and a large HOMO $\left(\mathrm{t}_{2 \mathrm{~g}}\right)$ - LUMO $\left(\mathrm{e}_{\mathrm{g}}\right)$ gap, limiting direct reactivity at the metal site. ${ }^{18}$ Inclusion of the aluminium-based ligand results in a significant distortion of geometry away from octahedral due to favourable, but weak, interactions in the secondary coordination sphere. This distortion leads to an unusual ground state destabilisation and raises the energy of the HOMO of the iron centre. This effect exposes an entirely new type of reactivity of the neutral low spin $\mathrm{d}^{6}$ centre. These complexes were found to selectively break the ortho $\mathrm{C}-\mathrm{H}$ bond in pyridine. Mechanistic studies reveal that the two metal centres act as a frustrated Fe-Al Lewis pair (FLP) ${ }^{19-23}$ leading to a deprotonation rather than oxidative addition pathway. ${ }^{24}$

The findings both compliment and expand upon the known nucleophilicity of anionic analogues such as $\left[\mathrm{Fe}\left(\eta^{5}-\mathrm{C}_{5} \mathrm{H}_{5}\right)(\mathrm{CO})_{2}\right]^{-}$. More broadly, these results suggest that the shape and electronic structure of transition metal centres can be modulated through incorporation of Lewis-acidic ligands, leading to perturbation of the electronic structure, and exposing new types of reactivity.

\section{C-H activation at coordinatively unsaturated systems}

Ozerov 2017
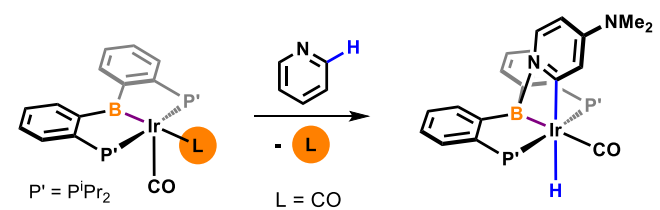

Nakao 2018
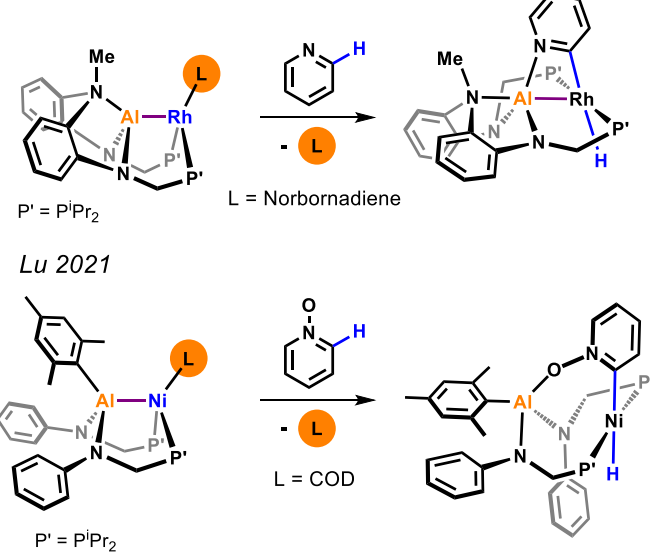

\section{C-H activation at a coordinatively saturated system}

this work:

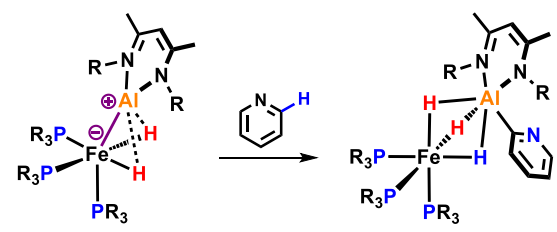

frustrated TM-M Lewis Pair

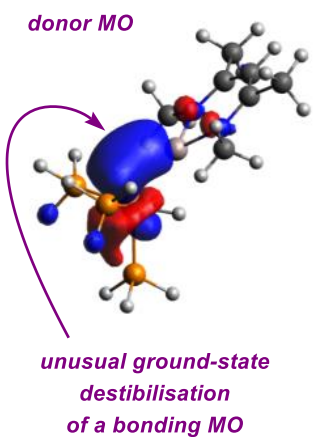

Figure 1. Well-defined bimetallic systems for the selective ortho $\mathrm{C}-\mathrm{H}$ activation of pyridines. Current systems that require ligand dissociation prior to bond activation versus a novel pathway occurring at a coordinatively saturate iron aluminylene system. 


\section{Synthesis and characterisation.}

Complexes $\mathbf{2} \mathbf{a}$ and $\mathbf{2} \mathbf{b}$ can be readily prepared by reacting $\mathrm{FeBr}_{2}, \mathrm{PMe}_{3}$ and the respective $\beta$-diketiminate aluminium hydrides 1 a $(R=$ Mesityl or Mes) or $\mathbf{1 b}(R=2,6$-Diisopropylphenyl or Dipp $)$ in toluene or benzene and were isolated in $80-90 \%$ yield (Figure 2). Both complexes exhibit a mutually coupled spin system comprised of one triplet and one doublet resonance in the ${ }^{31} \mathrm{P}\left\{{ }^{1} \mathrm{H}\right\}$ NMR spectra with an integration ratio of 1:2. These resonances are consistent with the magnetic non-equivalence of the axial and equatorial phosphine ligands. The most characteristic features in the ${ }^{1} \mathrm{H}$ NMR spectra are broad signals at $\delta_{H}=-13.08(2 a)$ or -13.20 (2b) ppm assigned to the bridging hydrides which are coupled to the quadrupolar I $=5 / 2{ }^{27} \mathrm{Al}$ nucleus.

Reduction of these precursors using magnesium turnings in THF affords complexes $\mathbf{3 a}$ and $\mathbf{3 b}$ in almost quantitative NMR yield. Both $\mathbf{3 a}$ and $\mathbf{3} \mathbf{b}$ can be isolated as dark red/orange crystalline solids. In contrast to complexes $\mathbf{2} \mathbf{a}-\mathbf{b}, \mathbf{3} \mathbf{3}-\mathbf{b}$ both show only one singlet resonance in the ${ }^{31} \mathrm{P}\left\{{ }^{1} \mathrm{H}\right\}$ and a well resolved quartet hydride resonance in the ${ }^{1} \mathrm{H}$ NMR spectra. The data are consistent with a highly symmetric structure in solution - an observation that could suggest fast ligand exchange on the NMR timescale.

a) preparation of the low-valent complexes $\mathbf{3} \mathbf{a}-\mathbf{b}$
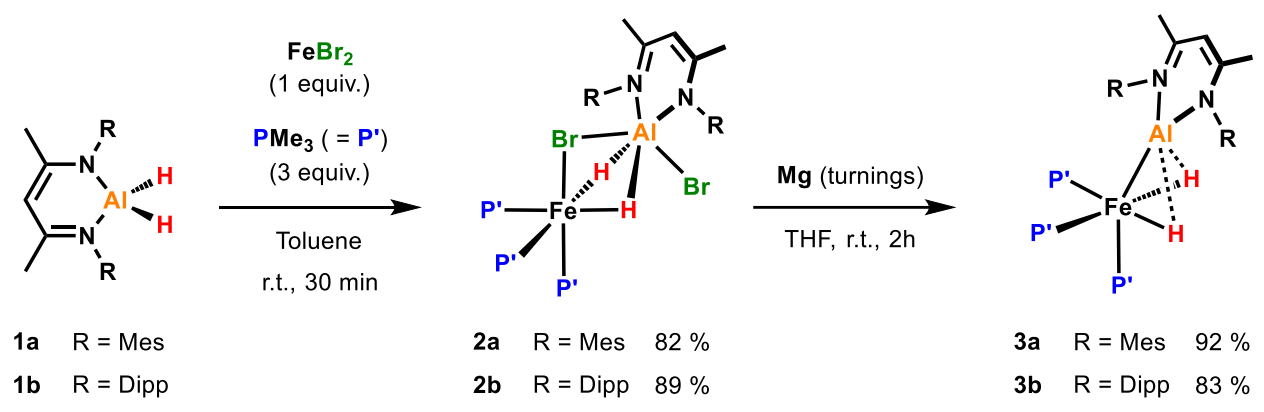

3a $\mathrm{R}=$ Mes $92 \%$

3b $\mathrm{R}=$ Dipp $83 \%$

b) solid-state structure of $\mathbf{2 b}$

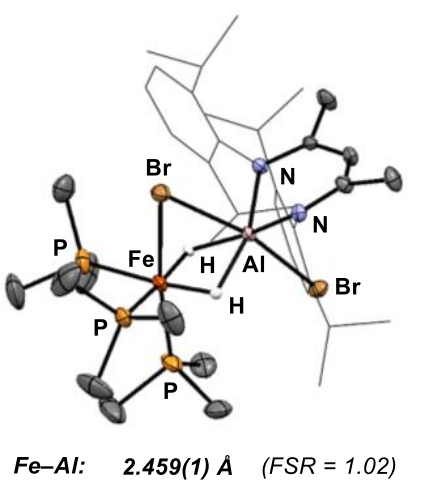

c) solid-state (left) and calculated (right) structures of $\mathbf{3 b}$

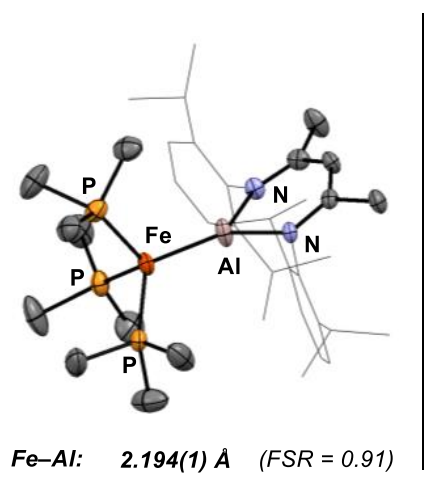

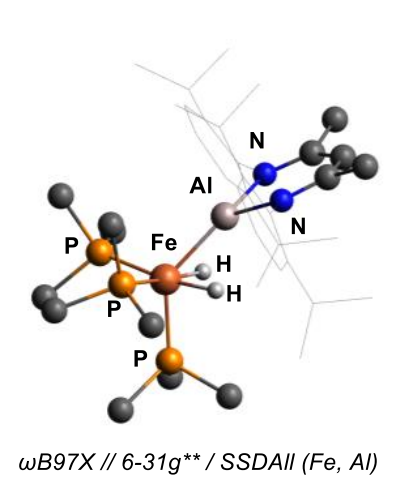

Figure 2. a) Preparation of complexes $\mathbf{2 a - b}$ and $\mathbf{3 a - b}$. b) X-ray structure of $\mathbf{2 b}$. c) X-ray and calculated structure of $3 b$. 


\section{Structure and bonding.}

Single crystals suitable for $\mathbf{X}$-ray diffraction could be obtained for all four compounds. Data for $\mathbf{2} \mathbf{b}$ and $\mathbf{3} \mathbf{b}$ are depicted in Figure 2. The position of the hydride ligands in $\mathbf{3 b}$ could not be refined but their presence is evident from the corresponding ${ }^{1} \mathrm{H}$ NMR spectrum. When comparing these structures, it becomes apparent that drastic changes in the Fe---Al intermetallic distances occur upon reduction. For example, a decrease of the Fe---Al distance from 2.459(1) $\AA$ in $\mathbf{2 b}$ to $2.194(1) \AA$ in $\mathbf{3 b}$ becomes visible in the solid-state structures. While the Fe---Al separation of $\mathbf{2} \mathbf{b}$ almost matches the sum of their covalent radii ${ }^{25}$ (formal shortness ratio ${ }^{26}(\mathrm{FSR})=$ $1.02)$ it is clearly below this value in $\mathbf{3 b}(F S R=0.91)$. Such short Fe---Al bond lengths appear to be diagnostic for an aluminylene ${ }^{27}$ metalloligand covalently bound to iron. ${ }^{28}$

Based on the experimental data it is evident that $\mathbf{2} \mathbf{a}-\mathbf{b}$ and $\mathbf{3} \mathbf{a}-\mathbf{b}$ are low-spin and diamagnetic 18 valence electron complexes. While $\mathbf{2 a - b}$ can be confidently described as $\sigma$-alane ${ }^{29}$ complexes, three extreme bonding scenarios $^{16}$ may be considered for the bimetallic species 3a-b (Scheme 3a): (A) a four-electron, $\eta^{2}: \eta^{2}$ coordination of $\mathrm{H}-\mathrm{Al}-\mathrm{H}$ to the 14 electron fragment $\left[\mathrm{Fe}\left(\mathrm{PMe}_{3}\right)_{3}\right],(\mathrm{B})$ two electron coordination of an aluminylene metalloligand to a 16 electron Fe(II) dihydride fragment, (C) strong polarisation of the TM-M bond resulting in a cationic Al metalloligand and an anionic iron dihydride fragment due to the electronegativity difference between the two metals $\left(\Delta \chi_{P}=0.22\right) \cdot{ }^{30,31}$

a) Extreme bonding descriptions for the low-valent Fe/Al complexes 3a-b

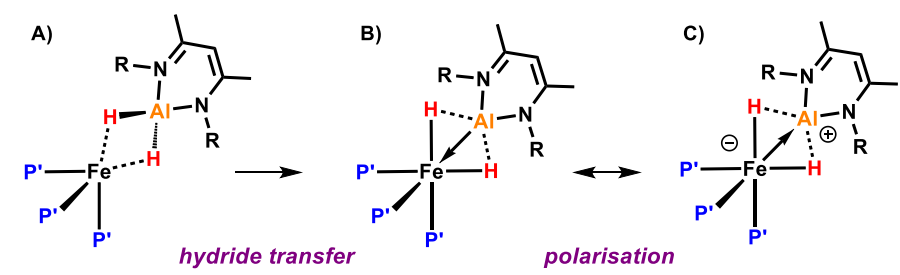

b) Calculated bond lenghts and NPA charges of $\mathbf{2} \boldsymbol{b}$ and $\mathbf{3} \boldsymbol{b}\left(R=\operatorname{Dipp}, P^{\prime}=P \mathrm{Pe}_{3}\right)$

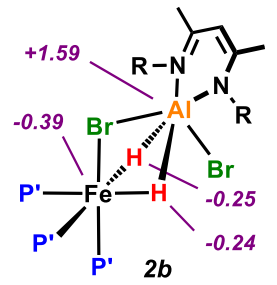

bond lengths $(A)$

Al-Fe 2.466

Al-H $\quad 1.838 / 1.855$

$\mathrm{Fe}-\mathrm{H} \quad 1.603 / 1.593$

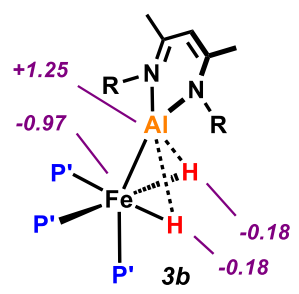

bond lengths $(A)$

Al-Fe $\quad 2.229$

Al-H $\quad 2.045 / 2.060$

$\mathrm{Fe}-\mathrm{H} \quad 1.570 / 1.576$ c) QTAIM analysis and WBIs of $\mathbf{2} \boldsymbol{b}$ and $\mathbf{3} \boldsymbol{b}$

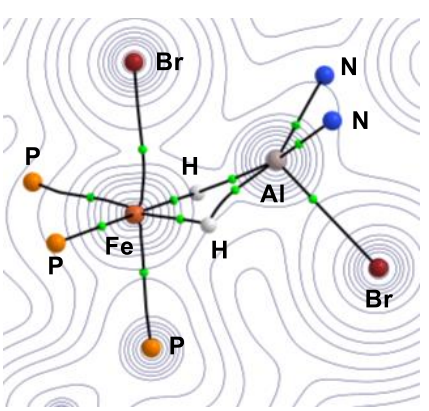

$2 b$

Wiberg Bond Indices

Al-Fe 0.14

Al-H $\quad 0.27 / 0.26$

$\mathrm{Fe}-\mathrm{H} \quad 0.44 / 0.45$

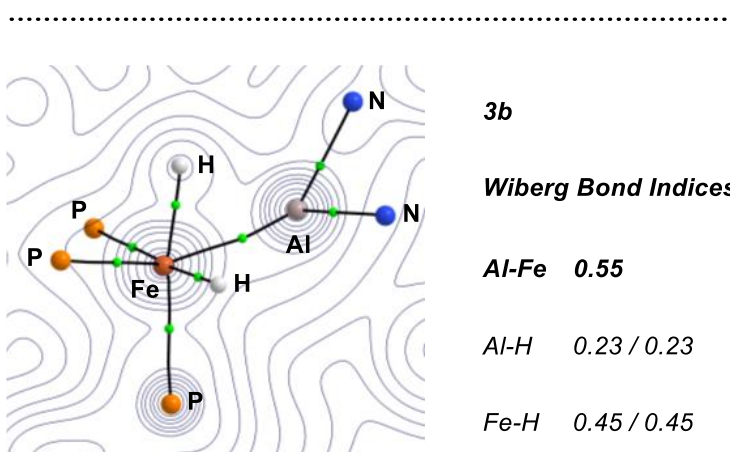

Figure 3. Analysis of the bonding in 3a-b. a) extreme bonding descriptions. b) calculated Fe---Al distances and NPA charges of $\mathbf{2 a}$ and $\mathbf{3 a}(\omega \mathrm{B} 97 \mathrm{X} / / \mathrm{6}-31 \mathrm{~g} * *(\mathrm{H}, \mathrm{C}, \mathrm{N}, \mathrm{P}) /$ SDDAll $(\mathrm{Fe}, \mathrm{Al}))$. c) QTAIM analysis and WBIs of $\mathbf{2 a}$ and 3a. 
More insight into the structure and bonding in these complexes was gained by DFT calculations and the optimised structure of $\mathbf{3 b}$ is depicted in Figure $2 c$. In complexes $\mathbf{3 a - b}$, the iron fragment adopts a pseudooctahedral coordination geometry in an all-cis configuration of the hydride and phosphine ligands, respectively (3b: L-Fe-L $=83.1-101.6^{\circ} ; \mathrm{L}=\mathrm{H}, \mathrm{PMe}_{3}$ ). Only the Al metalloligand deviates from this geometry being bent away from its axial position by about $45^{\circ}$. The calculated structures also reflect the short Fe---Al distances observed in the solid-state structure of $\mathbf{3 b}$ (Figure $3 \mathrm{~b}$ ). The $\mathrm{Al}-\mathrm{H}$ bonds in these species appear to be significantly longer in comparison to the parent dibromide complexes (e.g., 1.838 vs. $2.045 \AA$ ). The Wiberg bond indices (WBI) for the Fe---Al bond drastically increase from 0.14 in $\mathbf{2 b}$ to 0.55 in $\mathbf{3 b}$ while the WBls for the $\mathrm{Al}-\mathrm{H}$ bonds are slightly lower in $\mathbf{3 b}(0.23,0.23)$ than in $\mathbf{2} \mathbf{b}(0.27,0.26)$. These data suggest the presence of a direct metalmetal bond due to a preceding double $\mathrm{Al}-\mathrm{H}$ bond activation at the transition metal centre. ${ }^{30,32-35}$

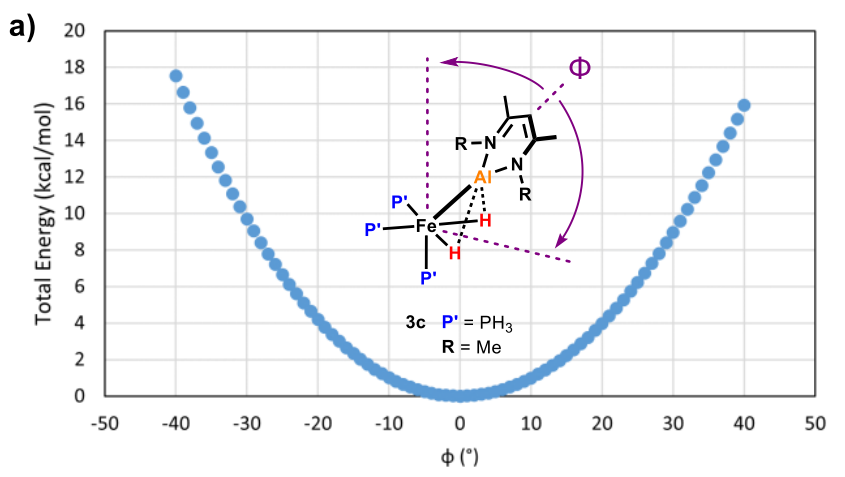

c)

$\Phi=0^{\circ}$

$\Phi=40^{\circ}$
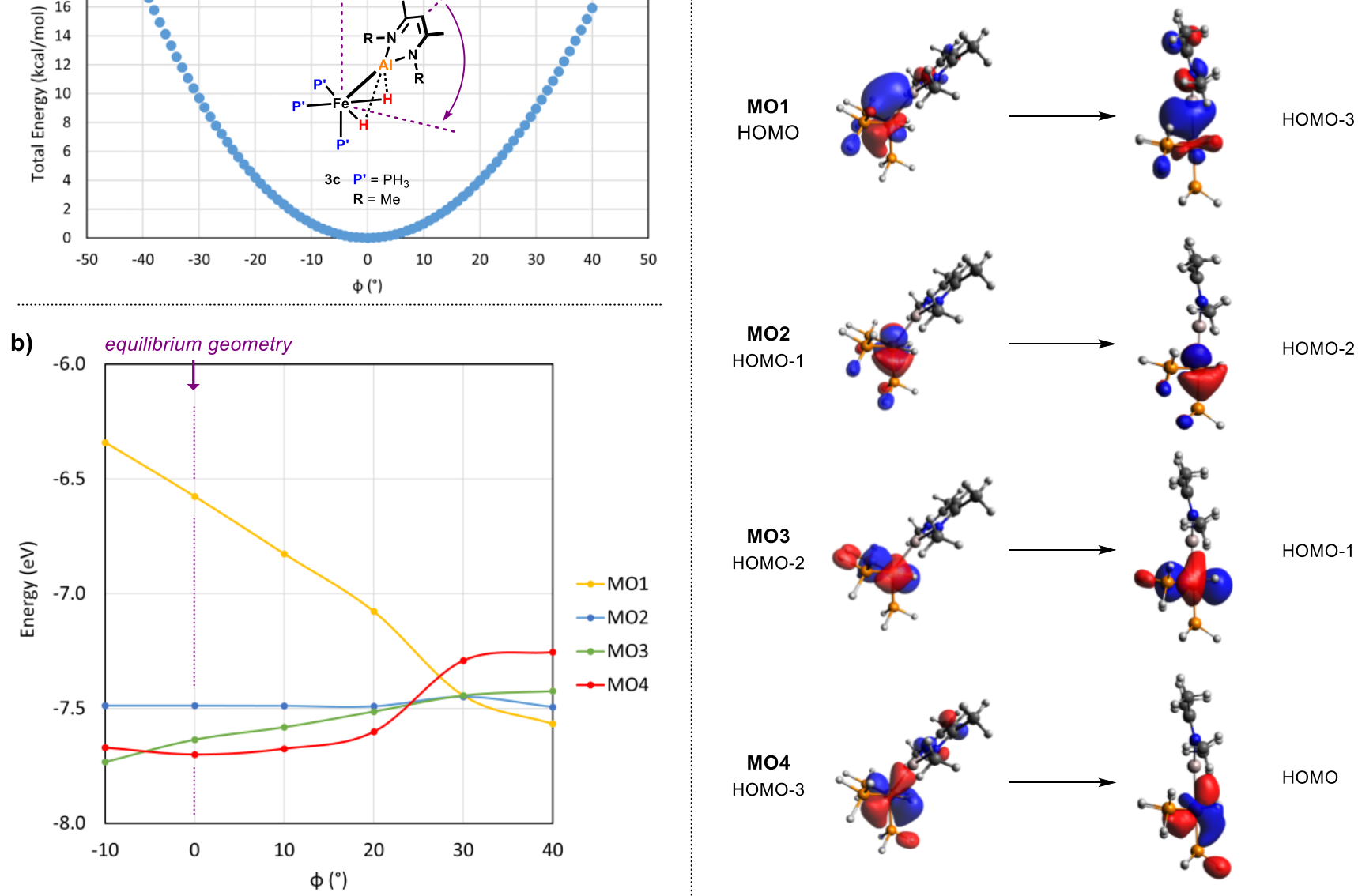

HOMO-1

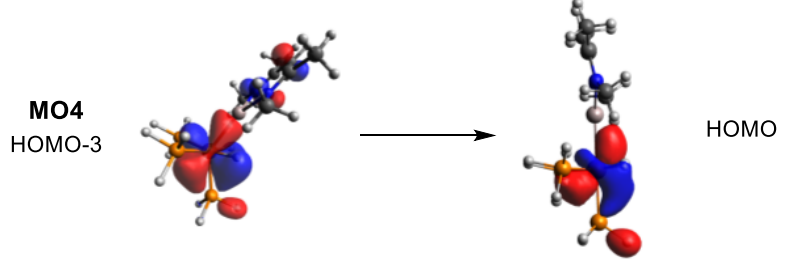

Figure 4. a) Energy profile for the relaxed scan of the Al-Fe- $\mathrm{P}_{\mathrm{ax}}$ angle in the simplified model complex 3c ( $\omega B$ B97X // 6-31g** $(\mathrm{H}, \mathrm{C}, \mathrm{N}, \mathrm{P}) /$ SDDAll $(\mathrm{Fe}, \mathrm{Al}))$. b) energies of the occupied frontier orbitals in 3c as function of the Al-Fe- $\mathrm{P}_{a x}$ bending angle. c) Orbital isosurfaces (isovalue $=0.05$ ) at $0^{\circ}$ (equilibrium structure) and $40^{\circ}$ (metalloligand in the axial position) bending angles. 
These findings are further underpinned by quantum theory atoms-in-molecules (QTAIM) calculations (Figure 3c). ${ }^{36}$ In $\mathbf{2} \mathbf{b}$, bond critical points (BCPs) are found between Fe and $\mathrm{H}, \mathrm{Al}$ and $\mathrm{H}$ but not between Fe and Al. In $\mathbf{3 b}$, the QTAIM analysis reveals BCPs between Fe and Al as well as Fe and $\mathrm{H}$ whereas no BCPs are found between $\mathrm{Al}$ and $\mathrm{H}$.

Analysis of the NPA charges in $\mathbf{3 b}$ reveals significant polarisation of the Fe-Al bond showing values of -0.97 for Fe and 1.25 for Al while negative charges on the hydrides are low $(-0.18 / 0.18)$. The large negative charge accumulation on Fe likely results from the strong electron donating nature of both the two hydrides and aluminylene ligand. This assumption is supported by ETS-NOCV calculations ${ }^{37}$ on $\mathbf{3 b}$ revealing that the donation from the hydrides and the aluminylene ligand to iron accounts for more than $64 \%\left(\Delta \rho_{1}=-74.7\right.$ $\mathrm{kcal} / \mathrm{mol})$ of the total orbital interaction energy $\left(\Delta \mathrm{E}_{\text {orb }}=-117.1 \mathrm{kcal} / \mathrm{mol}\right)$ whereas backdonation from the $\mathrm{Fe}-\mathrm{H}$ bonds to the empty Al p-orbitals were identified as the second $\left(\Delta \rho_{2}=-16.6 \mathrm{kcal} / \mathrm{mol}, 14 \%\right)$ and third $\left(\Delta \rho_{3}=-\right.$ $14.2 \mathrm{kcal} / \mathrm{mol}, 12 \%$ ) largest contributions to $\Delta \mathrm{E}_{\text {orb }}$ (see table $\mathrm{S} 5$ in the $\mathrm{SI}$ ). These secondary interactions are likely responsible for the bent position of the aluminylene metalloligand.

NBO calculations were used to gain further insight into the bonding in these complexes. For the sake of clarity, we considered a simplified model complex $\mathbf{3 c}\left(\mathrm{P}^{\prime}=\mathrm{PH}_{3}, \mathrm{R}=\mathrm{Me}\right)$ which, however, gives rise to highly similar frontier MOs as in 3a-b (see table S6 in the SI). The NBO analysis identifies a $\sigma$-bond between Fe $(4 \mathrm{~s}, 40.8 \%, 3 d$ $57.8 \%$ ) and $\mathrm{Al}$ ( $3 \mathrm{~s} 73.6 \%, 3 \mathrm{p} \mathrm{26.4 \% )}$ ) as main contributor to the HOMO, while the LUMO+2 comprises an empty p-orbital on aluminium and possesses antibonding character with respect to the Fe-Al $\sigma$-bond. The HOMO is significantly higher (about $1.0 \mathrm{eV}$ ) in energy than the lower MOs which are predominantly non-bonding and possess largely 3d-character (HOMO-1 to HOMO-3). This difference appears to be a consequence of the distorted coordination geometry and vanishes when the metalloligand is moved towards the axial position (Figure 4). 


\section{Intramolecular C-H activation.}

The complex 3a was found to undergo an intramolecular $\mathrm{C}-\mathrm{H}$ activation affording the cyclometalated complex 4a (Figure 5a). Heating a toluene- $d_{8}$ solution of $3 a$ to $80^{\circ} \mathrm{C}$ results in slow formation of a new species as revealed by a growing new singlet resonance at $\delta_{\mathrm{P}}=30.0 \mathrm{ppm}$ in the ${ }^{31} \mathrm{P}$ NMR spectrum. In the ${ }^{1} \mathrm{H}$ NMR, $4 \mathrm{a}$ gives rise to a new hydride signal (broadened quartet) that integrates to $3 \mathrm{H}$. The reaction was monitored over time and complete consumption of the starting material observed after $24 \mathrm{~h}$. The new species was formed in 71\% NMR yield. Crystals suitable for X-ray diffraction could be grown by diffusion of tetramethylsilane into a saturated solution of $n$-pentane and the solid-state structure of $4 \mathrm{a}$ is depicted in Figure $5 \mathrm{~b}$. Heating a solution of $\mathbf{3 b}$ in toluene- $d_{8}$ to $80{ }^{\circ} \mathrm{C}$ only results in the slow decomposition of this complex and the formation untraceable species.

a) intramolecular $\mathrm{C}-\mathrm{H}$ activation / cyclometalation of $\mathbf{3 a}$

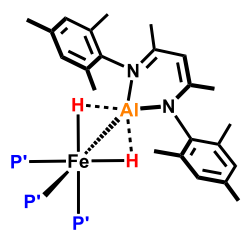

$3 \mathbf{a}$

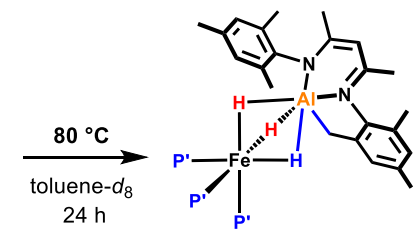

4a $>71 \%$ NMR yield b) $X$-Ray structure of $4 a$

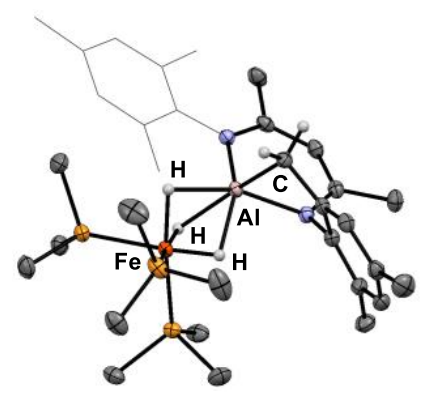

c) calculated free energy profile

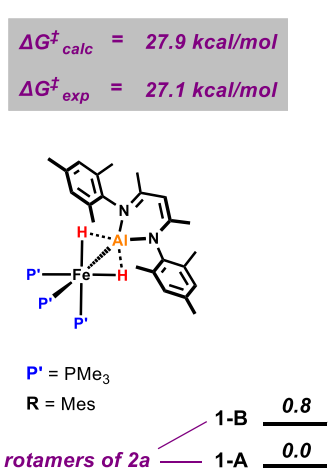

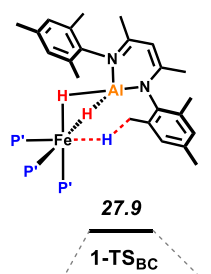

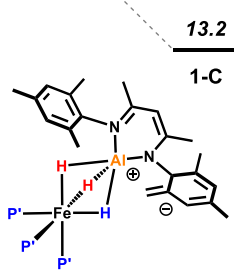

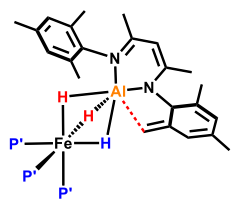

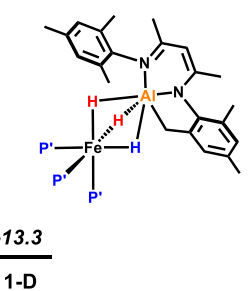

d) frontier MOs in 1-B

LUMO+6

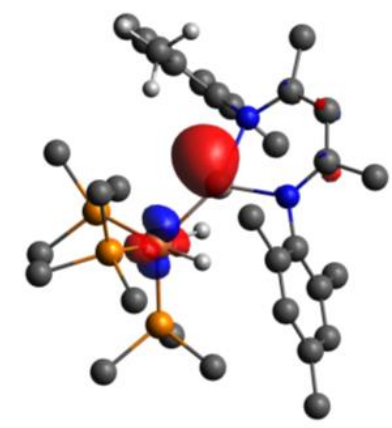

номо

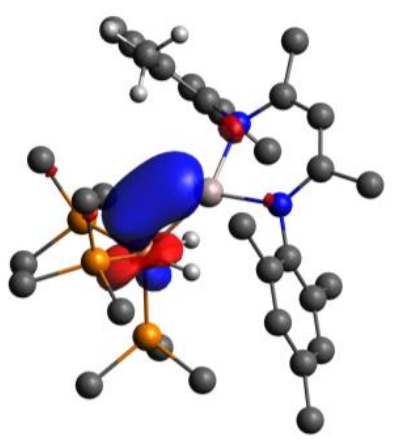

Figure 5. a) Intramolecular $\mathrm{C}-\mathrm{H}$ activation of $\mathbf{3 a}$, b) X-ray structure of $\mathbf{4 a}$, c) calculated free energy profile for the conversion of 3a to 4a (B3PW91 / PCM (toluene) / D3 // 6-31g** (H,C,N,P) / SDDAll (Fe,Al)). Energies are given in $\mathrm{kcal} / \mathrm{mol}$. d) acceptor (LUMO+6) and donor (HOMO) orbitals in intermediate 1-B.

More insight into the conversion of $\mathbf{3 a}$ to $\mathbf{4 a}$ was gained from a combination of kinetic experiments and DFT calculations. ${ }^{13}$ Experimentally, the reaction was found to be first order with respect to 3a. An Eyring analysis over a temperature range of $60-100{ }^{\circ} \mathrm{C}$ gave the activation parameters $\Delta \mathrm{H}^{\ddagger}=23.4 \pm 0.5 \mathrm{kcal} \mathrm{mol}^{-1}$ and $\Delta \mathrm{S}^{\ddagger}=$ $12.5 \pm 1.3 \mathrm{cal} \mathrm{mol}^{-1} \mathrm{~K}^{-1}$ which correspond to an associated $\Delta \mathrm{G}_{298 \mathrm{~K}^{\ddagger}}=27.1 \pm 0.8 \mathrm{kcal} \mathrm{mol}^{-1}$. DFT calculations were benchmarked against the experimental data. Best results were obtained by using the B3PW91 functional and a 
6-31g** ( $\mathrm{H}, \mathrm{C}, \mathrm{N}, \mathrm{P})$ / SDDAll (Fe,Al) basis set. Solvent (PCM, Benzene) and dispersion corrections (D3) were directly included in the optimisation of the stationary points.

The calculated free energy profile for the intramolecular $\mathrm{C}-\mathrm{H}$ activation is shown in Figure 5c. The reaction sequence is initiated by a slight rotation of the aluminylene ligand around the Fe---Al axes (1-A to 1-B) followed by a deprotonation of the mesityl $\mathrm{CH}_{3}$ group by the iron metal centre (1-TS $\mathrm{SC}_{\mathrm{BC}}$ ). Intermediate 1-C features the $\mathrm{Fe}-\left(\mu-\mathrm{H}_{3}\right)$-Al bridging motif and the deprotonated mesityl residue. Another slight conformational change initiates the $\mathrm{Al}-\mathrm{C}$ bond formation (1-TS $\mathrm{CD}$ ) and leads to the cyclometalated product (1-D). Formation of the product is exergonic by $-13.3 \mathrm{kcal} \mathrm{mol}^{-1}$ with an overall barrier of $27.9 \mathrm{kcal} \mathrm{mol}^{-1}$ being in good agreement to the experimental value $\left(27.1 \pm 0.8 \mathrm{kcal} \mathrm{mol}^{-1}\right)$.

Analysis of the frontier MOs reveals that the HOMO in the ground state of 3a (Figure $5 \mathrm{~d}$ ) acts as electron donor for the reductive deprotonation of the $\mathrm{CH}_{3}$ group in 1-TS $\mathrm{BC}$ while an empty p-orbital at Al (LUMO+6, Figure $5 \mathrm{~d}$ ) acts as electron acceptor for the deprotonated $\mathrm{CH}_{2}$ group (1-TS $\mathbf{C D}$ ) to form the $\mathrm{Al}-\mathrm{C}$ bond in the final product (1-D).

\section{Intermolecular C-H Activation}

Complexes $\mathbf{3} \mathbf{a}$ and $\mathbf{3} \mathbf{b}$ are also capable of promoting intermolecular $\mathbf{C}-\mathrm{H}$ activation. For example, $\mathbf{3 a}$ readily reacts with pyridine ( 1 equiv., $\mathrm{C}_{6} \mathrm{D}_{6}$, room temperature) resulting in the selective $\mathrm{C}-\mathrm{H}$ activation in the 2 position of the heterocycle (> 95\% NMR yield, Figure 6a). Like $4 \mathbf{a}, \mathbf{5 a}$ exhibits a sharp singlet resonance in the ${ }^{31} \mathrm{P}\left\{{ }^{1} \mathrm{H}\right\} \mathrm{NMR}$ spectrum at $\delta_{\mathrm{P}}=29.6 \mathrm{ppm}$ as well as a broadened quartet hydride signal at $\delta_{\mathrm{H}}=-15.33 \mathrm{ppm}$ in the ${ }^{1} \mathrm{H}$ NMR spectrum. The reaction of $\mathbf{2 b}$ with pyridine required more forcing reaction conditions $\left(40^{\circ} \mathrm{C}, 10\right.$ equiv. of pyridine, $18 \mathrm{~h}$ ) but led to the analogue product $\mathbf{5 b}$ in about $80 \%$ NMR yield. Crystals suitable for X-ray diffraction could be obtained for $\mathbf{5 b}$ and the solid-state structure confirms the ortho $\mathrm{C}-\mathrm{H}$ activation and $\mathrm{C}-\mathrm{Al}$ bond formation in 2-position of the pyridine heterocycle (Figure 6b).

A small array of substrates was investigated. Employing pyridines with different substituents in the 4-postion $\left(\mathrm{R}=\mathrm{Me}, \mathrm{Ph}, \mathrm{NMe}_{2}\right)$ under the same conditions did not show any change in the reactivity or selectivity of the $\mathrm{C}-$ $\mathrm{H}$ activation with $\mathbf{3 a}$, in all cases giving products that arise from substitution at the 2-position (Figure $6 \mathrm{c}$ ). On the other hand, 2-phenylpyridine did not react with 3a, presumably due to steric interference of the phenyl substituent with the ligand system on aluminium.

DFT-calculations on the ortho $\mathrm{C}-\mathrm{H}$ activation of pyridine suggest a similar reaction pathway as for the intramolecular $\mathrm{C}-\mathrm{H}$ activation of $\mathbf{3 a}$ (Figure 6c). Again, a two-step mechanism has been identified that proceeds via the deprotonation of pyridine substrate. Coordination of the pyridine nitrogen to the aluminium centre controls the site selectivity of the reaction. NBO calculations reveal that the coordination of pyridine also facilitates bond breaking. In 2-A, the Fe-Al bond becomes more polarised in comparison to 1-B and the Wiberg bond index drops (see tables S7 and S8 in the $\mathrm{SI}$ ). The following transition state 2-TS $\mathbf{A B}_{\mathrm{AB}}$ is significantly lower in energy than for the intramolecular deprotonation of the mesityl $\mathrm{CH}_{3}$ group in 3a (14.7 vs. 27.9 
$\mathrm{kcal} / \mathrm{mol}$ ) being in line with a fast reaction at room temperature. Both, the intermediates after coordination (2A, $0.0 \mathrm{kcal} / \mathrm{mol}$ ) and deprotonation $(2-\mathbf{B}, 0.8 \mathrm{kcal} / \mathrm{mol})$ of the pyridine appear to be almost thermoneutral in comparison to the starting materials. However, a final switch from $\mathrm{N}$ - to $\mathrm{C}$-coordination of the deprotonated pyridine is facile $\left(\mathbf{2}-\mathrm{TS}_{\mathrm{BC}}\right.$, barrier of $\left.5.5 \mathrm{kcal} / \mathrm{mol}\right)$ and highly exergonic due to formation of the $\mathrm{Al}-\mathrm{C}$ bond in $\mathbf{2}-\mathrm{C}$ $(-20.7 \mathrm{kcal} / \mathrm{mol})$.

A comparison of the reaction rates using an excess of pyridine or pyridine- $d_{5}$ in two independent reactions gave an unusually large kinetic isotope effect (KIE) of $14.0 \pm 0.2$ at $297 \mathrm{~K}$. The experimentally observed $k_{H} / k_{D}$ value likely results from a large classical KIE including a significant contribution of quantum tunnelling. ${ }^{38}$ The rate determining elementary step (2-A to $\mathbf{2}-\mathbf{B}$ ) is nearly thermoneutral with a centred transition state along the reaction coordinate and thus a maximum primary KIE (up to 7-8) may be expected. ${ }^{38,39}$ On the other hand, KIEs greater than 10 are generally considered to be caused by quantum tunneling and are diagnostic for proton transfer reactions. ${ }^{40-43}$ Both assumptions are in agreement with the calculated mechanism in Figure $6 \mathrm{c}$ and support a non-oxidative addition pathway.

a) pyridine ortho $\mathrm{C}-\mathrm{H}$ activation

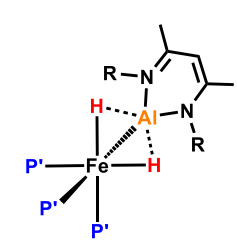

3a $\mathrm{R}=$ Mes $\mathrm{P}^{\prime}=\mathrm{PMe}_{3}$

3b $\mathrm{R}=\mathrm{Dipp} \quad \mathrm{P}^{\prime}=\mathrm{PMe}_{3}$

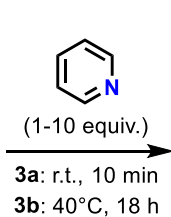

$\mathrm{C}_{6} \mathrm{D}_{6}$ $5 a$

\section{$5 a$}

$5 b$
$6 a$

$$
\text { as }
$$$$
7 a
$$

$$
\begin{array}{lllr}
\mathbf{5 a} & \mathrm{R}=\text { Mes } & \mathrm{R}^{\prime}=\mathrm{H} & (>95 \%) \\
\mathbf{5 b} & \mathrm{R}=\mathrm{Dipp} & \mathrm{R}^{\prime}=\mathrm{H} & (80 \%) \\
\mathbf{6 a} & \mathrm{R}=\text { Mes } & \mathrm{R}^{\prime}=\mathrm{Me} & (>95 \%) \\
\mathbf{7 a} & \mathrm{R}=\text { Mes } & \mathrm{R}^{\prime}=\mathrm{Ph} & (>95 \%) \\
\mathbf{8 a} & \mathrm{R}=\text { Mes } & \mathrm{R}^{\prime}=\mathrm{NMe}_{2} & (>95 \%)
\end{array}
$$

b) solid-state structure of $\mathbf{5 b}$
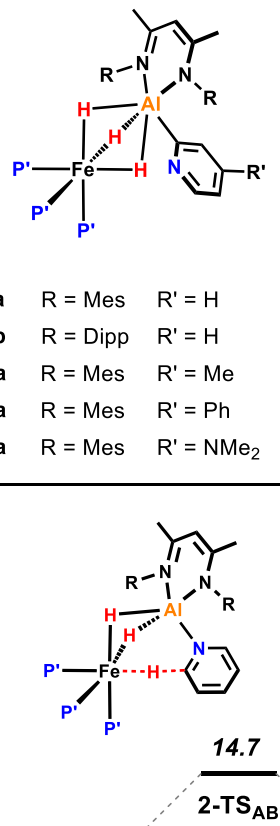

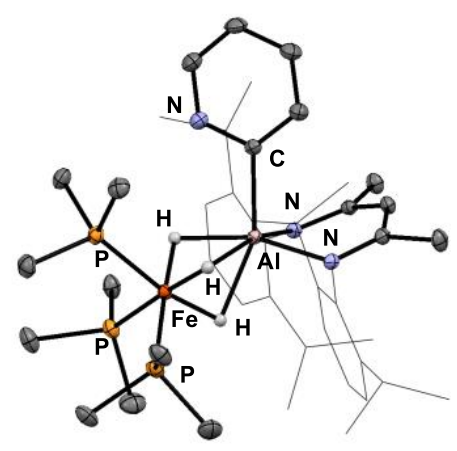

c) calculated free energy profile

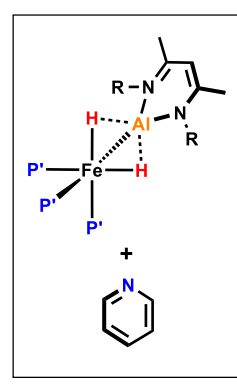

$\mathbf{P}^{\prime}=\mathrm{PMe}_{3}$

$\mathbf{R}=$ Mes $\frac{0.0}{3 a+\text { pyridine }}-\frac{0.0}{2-\mathrm{A}}$

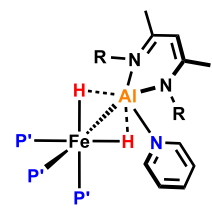

2-TS $A B$

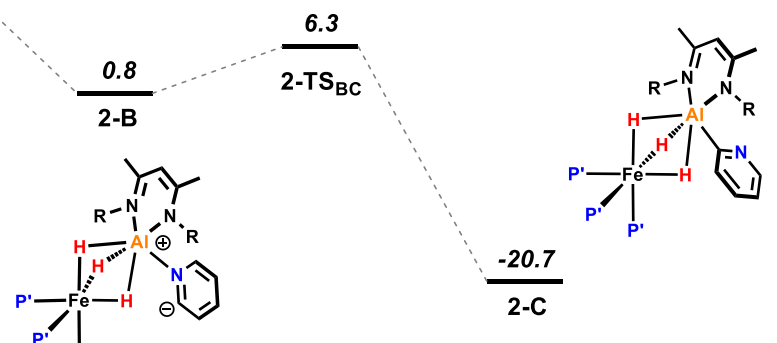

Figure 6. a) Pyridine ortho $\mathrm{C}-\mathrm{H}$ activation with 3a-b (NMR Yields are given in parentheses), b) X-ray structure of $\mathbf{5 b}$, c) calculated free energy profile for the conversion of 3a to 5a (B3PW91 / PCM (benzene) / D3 // 6-31g** $(\mathrm{H}, \mathrm{C}, \mathrm{N}, \mathrm{P})$ / SDDAll $(\mathrm{Fe}, \mathrm{Al}))$. Energies are given in $\mathrm{kcal} / \mathrm{mol}$. 


\section{Conclusions.}

In summary, we described two well-defined bimetallic Fe-Al complexes that possess a distorted octahedral geometry. This distortion leads to an unusual ground state destabilisation and raises the energy of the HOMO (the Fe-Al bond). Consequently, the HOMO becomes accessible for an encounter substrate and leads to an enhanced reactivity of these complexes including intramolecular $\mathrm{sp}^{3} \mathrm{C}-\mathrm{H}$ activation as well as in the selective ortho $\mathrm{C}-\mathrm{H}$ activation of pyridine substrates. These reactions were found to follow a novel cooperative mechanism in which a reductive deprotonation of the $\mathrm{C}-\mathrm{H}$ bond was identified as key elementary step. We could show that the Fe-Al bonds these complexes are highly polarised and react as a bimetallic frustrated Lewis pair in which the destabilised HOMO acts as Lewis donor orbital while empty p-orbitals on Al serve as Lewis acceptors. The reaction leads to the formation of a Fe-H and $\mathrm{Al}-\mathrm{C}$ bonds. These results may lay the foundation for the rational design of future catalytic systems with prospects in the field of base-metal catalysis.

\section{Acknowledgments.}

We are grateful to the FWF for provision of an Erwin Schrödinger Fellowship (NG). 


\section{References}

(1) Khusnutdinova, J. R.; Milstein, D. Metal-Ligand Cooperation. Angew. Chemie Int. Ed. 2015, 54, 1223612273.

(2) Elsby, M. R.; Baker, R. T. Strategies and Mechanisms of Metal-Ligand Cooperativity in First-Row Transition Metal Complex Catalysts. Chem. Soc. Rev. 2020, 49, 8933-8987.

(3) Maity, A.; Teets, T. S. Main Group Lewis Acid-Mediated Transformations of Transition-Metal Hydride Complexes. Chem. Rev. 2016, 116, 8873-8911.

(4) Takaya, J. Catalysis Using Transition Metal Complexes Featuring Main Group Metal and Metalloid Compounds as Supporting Ligands. Chem. Sci. 2021, 12, 1964-1981.

(5) Bouhadir, G.; Bourissou, D. Complexes of Ambiphilic Ligands: Reactivity and Catalytic Applications. Chem. Soc. Rev. 2016, 45, 1065-1079.

(6) Chirik, P.; Morris, R. Getting Down to Earth: The Renaissance of Catalysis with Abundant Metals. Acc. Chem. Res. 2015, 48, 2495-2495.

(7) Fürstner, A. Iron Catalysis in Organic Synthesis: A Critical Assessment of What It Takes To Make This Base Metal a Multitasking Champion. ACS Cent. Sci. 2016, 2, 778-789.

(8) Holland, P. L. Distinctive Reaction Pathways at Base Metals in High-Spin Organometallic Catalysts. Acc. Chem. Res. 2015, 48, 1696-1702.

(9) Arevalo, R.; Chirik, P. J. Enabling Two-Electron Pathways with Iron and Cobalt: From Ligand Design to Catalytic Applications. J. Am. Chem. Soc. 2019, 141, 9106-9123.

(10) Graziano, B. J.; Vollmer, M. V.; Lu, C. C. Cooperative Bond Activation and Facile Intramolecular Aryl Transfer of Nickel-Aluminum Pincer-type Complexes. Angew. Chemie Int. Ed. 2021, 60, 15087-15094.

(11) Hara, N.; Saito, T.; Semba, K.; Kuriakose, N.; Zheng, H.; Sakaki, S.; Nakao, Y. Rhodium Complexes Bearing PAIP Pincer Ligands. J. Am. Chem. Soc. 2018, 140, 7070-7073.

(12) Shih, W.-C.; Ozerov, O. V. Selective Ortho C-H Activation of Pyridines Directed by Lewis Acidic Boron of PBP Pincer Iridium Complexes. J. Am. Chem. Soc. 2017, 139, 17297-17300.

(13) Hara, N.; Aso, K.; Li, Q.-Z.; Sakaki, S.; Nakao, Y. C2-Selective Alkylation of Pyridines by RhodiumAluminum Complexes. Tetrahedron 2021, 95, 132339.

(14) Cao, Y.; Shih, W.-C.; Bhuvanesh, N.; Zhou, J.; Ozerov, O. V. Cooperative C-H Activation of Pyridine by PBP Complexes of Rh and Ir Can Lead to Bridging 2-Pyridyls with Different Connectivity to the B-M Unit. Chem. Sci. 2021, 12, 14167-14173.

(15) Liu, J.; Li, Y.; Jiang, J.; Liu, Y.; Ke, Z. Mechanism of Ir-Mediated Selective Pyridine o-C-H Activation: The Role of Lewis Acidic Boryl Group. ACS Catal. 2021, 11, 6186-6192.

(16) Butler, M. J.; Crimmin, M. R. Magnesium, Zinc, Aluminium and Gallium Hydride Complexes of the 
Transition Metals. Chem. Commun. 2017, 53, 1348-1365.

(17) Crabtree, R. H. The Organometallic Chemistry of the Transition Metals; John Wiley \& Sons, Inc.: Hoboken, NJ, USA, 2005.

(18) Hartwig, J. F. Organotransition Metal Chemistry: From Bonding to Catalysis; University Science Books: Sausalito, CA, 2010.

(19) Chatterjee, B.; Chang, W.-C.; Jena, S.; Werlé, C. Implementation of Cooperative Designs in Polarized Transition Metal Systems-Significance for Bond Activation and Catalysis. ACS Catal. 2020, 10, 1402414055.

(20) Mankad, N. P. Diverse Bimetallic Mechanisms Emerging from Transition Metal Lewis Acid/Base Pairs: Development of Co-Catalysis with Metal Carbenes and Metal Carbonyl Anions. Chem. Commun. 2018, $54,1291-1302$.

(21) Navarro, M.; Campos, J. Chapter 3 - Bimetallic Frustrated Lewis Pairs. In Advances in Organometallic Chemistry; Elsevier: Oxford; 2021; Vol. 75, pp 95-148.

(22) Hidalgo, N.; Alférez, M. G.; Campos, J. Frustrated Lewis Pairs Based on Transition Metals. In Frustrated Lewis Pairs; Slootweg, C. J.; Jupp, A.R., Eds.; Springer: Cham., 2021; Vol. 2, pp 319-359.

(23) Bauer, J.; Braunschweig, H.; Dewhurst, R. D. Metal-Only Lewis Pairs with Transition Metal Lewis Bases. Chem. Rev. 2012, 112, 4329-4346.

(24) Li, Y.; Hou, C.; Jiang, J.; Zhang, Z.; Zhao, C.; Page, A. J.; Ke, Z. General $\mathrm{H}_{2}$ Activation Modes for Lewis Acid-Transition Metal Bifunctional Catalysts. ACS Catal. 2016, 6, 1655-1662.

(25) Pauling, L. Atomic Radii and Interatomic Distances in Metals. J. Am. Chem. Soc. 1947, 69, 542-553.

(26) Multiple Bonds Between Metal Atoms; Cotton, F. A., Murillo, C. A., Walton, R. A., Eds.; Springer-Verlag: New York, 2005.

(27) Cui, C.; Roesky, H. W.; Schmidt, H.-G.; Noltemeyer, M.; Hao, H.; Cimpoesu, F. Synthesis and Structure of a Monomeric Aluminum(I) Compound [ $\left.\left\{\mathrm{HC}(\mathrm{CMeNAr})_{2}\right\} \mathrm{Al}\right]\left(\mathrm{Ar}=2,6-\mathrm{iPr}_{2} \mathrm{C}_{6} \mathrm{H}_{3}\right)$ : A Stable Aluminum Analogue of a Carbene. Angew. Chemie - Int. Ed. 2000, 39, 4274-4276.

(28) Kong, R. Y.; Crimmin, M. R. $1^{\text {st }}$ Row Transition Metal Aluminylene Complexes: Preparation, Properties and Bonding Analysis. Dalt. Trans. 2021, 50, 7810-7817.

(29) Riddlestone, I. M.; Edmonds, S.; Kaufman, P. A.; Urbano, J.; Bates, J. I.; Kelly, M. J.; Thompson, A. L.; Taylor, R.; Aldridge, S. $\sigma$-Alane Complexes of Chromium, Tungsten, and Manganese. J. Am. Chem. Soc. 2012, 134, 2551-2554.

(30) Ekkert, O.; White, A. J. P.; Toms, H.; Crimmin, M. R. Addition of Aluminium, Zinc and Magnesium Hydrides to Rhodium(III). Chem. Sci. 2015, 6, 5617-5622.

(31) Escomel, L.; Del Rosal, I.; Maron, L.; Jeanneau, E.; Veyre, L.; Thieuleux, C.; Camp, C. Strongly Polarized Iridium $^{\delta-}-$ Aluminum ${ }^{\delta+}$ Pairs: Unconventional Reactivity Patterns Including $\mathrm{CO}_{2}$ Cooperative Reductive 
Cleavage. J. Am. Chem. Soc. 2021, 143, 4844-4856.

(32) Abdalla, J. A. B.; Caise, A.; Sindlinger, C. P.; Tirfoin, R.; Thompson, A. L.; Edwards, A. J.; Aldridge, S. Structural Snapshots of Concerted Double E-H Bond Activation at a Transition Metal Centre. Nat. Chem. 2017, 9, 1256-1262.

(33) Turner, J.; Abdalla, J. A. B.; Bates, J. I.; Tirfoin, R.; Kelly, M. J.; Phillips, N.; Aldridge, S. Formation of SubValent Carbenoid Ligands by Metal-Mediated Dehydrogenation Chemistry: Coordination and Activation of $\mathrm{H}_{2} \mathrm{Ga}\left\{(\mathrm{NDippCMe})_{2} \mathrm{CH}\right\}$. Chem. Sci. 2013, 4, 4245.

(34) O’Neill, M.; A. Addy, D.; Riddlestone, I.; Kelly, M.; Phillips, N.; Aldridge, S. Borane to Boryl Hydride to Borylene Dihydride: Explicit Demonstration of Boron-to-Metal $\alpha$-Hydride Migration in Aminoborane Activation. J. Am. Chem. Soc. 2011, 133, 11500-11503.

(35) Alcaraz, G.; Grellier, M.; Sabo-Etienne, S. Bis $\sigma$-Bond Dihydrogen and Borane Ruthenium Complexes: Bonding Nature, Catalytic Applications, and Reversible Hydrogen Release. Acc. Chem. Res. 2009, 42, 1640-1649.

(36) Bader, R. F. W. A Quantum Theory of Molecular Structure and Its Applications. Chem. Rev. 1991, 91, 893-928.

(37) Mitoraj, M. P.; Michalak, A.; Ziegler, T. A Combined Charge and Energy Decomposition Scheme for Bond Analysis. J. Chem. Theory Comput. 2009, 5, 962-975.

(38) Gómez-Gallego, M.; Sierra, M. A. Kinetic Isotope Effects in the Study of Organometallic Reaction Mechanisms. Chem. Rev. 2011, 111, 4857-4963.

(39) Westheimer, F. H. The Magnitude of the Primary Kinetic Isotope Effect for Compounds of Hydrogen and Deuterium. Chem. Rev. 1961, 61, 265-273.

(40) Bell, R. P. Liversidge Lecture. Recent Advances in the Study of Kinetic Hydrogen Isotope Effects. Chem. Soc. Rev. 1974, 3, 513.

(41) Bell, R. P. The Tunnel Effect in Chemistry; Springer US: Boston, MA, 1980.

(42) Caldin, E. F. Tunneling in Proton-Transfer Reactions in Solution. Chem. Rev. 1969, 69, 135-156.

(43) Limbach, H.-H.; Miguel Lopez, J.; Kohen, A. Arrhenius Curves of Hydrogen Transfers: Tunnel Effects, Isotope Effects and Effects of Pre-Equilibria. Philos. Trans. R. Soc. B Biol. Sci. 2006, 361, 1399-1415. 